MISCELÁNEOS Rev Chil Salud Pública 2013; Vol 17 (3): 298-306

\section{LA FINITUD Y LOS LÍMITES DEL SUFRIMIENTO HUMANO: UNA LECTURA DE AMOUR DE MICHAEL HANEKE}

\author{
THE FINALITY AND THE LIMITS OF HUMAN SUFFERING: \\ An interpretation of Amour by Michael HaNeke
}

\section{RESUMEN}

Este escrito analiza la temática de la muerte digna a partir de la película de Michael Haneke, Amour. Tomando esa cintacomo eje articulador, se propone una reflexión crítica sobre el lugar que ocupa el sufrimiento y el dolor que antecede a la muerte en la sociedad contemporánea, valiéndose, para ello, de autores como Séneca en sus Cartas Morales a Lucilio, Norbert Elias en La soledad de los moribundos, y del último libro publicado por André Gorz, Carta a D. Este artículo pretende dar visibilidad a un tema que la sociedad contemporánea se obstina en ocultar, como es el sufrimiento que antecede a la muerte, y de subrayar la importancia que los lazos afectivos, en este caso el amor conyugal, pueden tener en ese proceso.

Palabras clave: Amor, muerte, moribundos, respeto, dignidad, Haneke.

\section{ABSTRACT}

This paper analyzes the issue of the death with dignity, having as starting point Michael Haneke's film, Amour. Taking that movie as main reference, it is proposed a critical reflection concerning the place of the sufferings and pains that precede death in contemporary society; also using for this purpose works such as Seneca's Letters to Lucilius, Norbert Elias' The Loneliness of the Dying, and the last book published by André Gorz, Letter to D. This article aims to give visibility to something that contemporary society persists in hiding: the suffering that precedes death; but it also aims to emphasize the importance that loving relationships, in this case the conjugal love, can have in that process.

Key Words: Love, death, dying, respect, dignity, Haneke

\section{SANDRa CAPONI}

Departamento de Sociologia y Ciencias Políticas Universidad Federal de Santa Catarina sandracaponi@ gmail.com
La muerte no tiene nada terrible.

Se cae en sueños y el mundo desaparece. Lo terrible son los dolores de los moribundos. 


\begin{abstract}
Haneke ha rodado la historia de amor más auténtica del cine reciente.

Sergi Sanchez. La razón, Madrid
\end{abstract}

Esta durísima película nos interpela de un modo muy particular. Nos sitúa en el corazón del mayor de los miedos humanos, el miedo a la decrepitud, al sufrimiento físico, al dolor y a la muerte. Un tema que, de un modo u otro, todos deberemos enfrentar en algún momento de nuestras vidas, ya sea porque debamos vivir en nuestra propia piel la decadencia y la incapacidad física, o porque debamos asistir a ese sufrimiento entre nuestros afectos más próximos. Haneke (1) aborda el tema que obsesionó a los filósofos más diversos, desde Platón y Séneca (2) hasta los últimos textos publicados en revistas de bioética, desde una perspectiva completamente innovadora. Amour nos presenta un retrato conmovedor sobre la vejez, la decadencia y la muerte, sin hacer uso de esas estructuras narrativas a las cuales el cine nos tiene tan mal acostumbrados.

La película de Haneke, ganadora del festival de Cannes de 2012, es un retrato simple, pero al mismo tiempo sutil y soberbio, de un drama cotidiano que nuestra sociedad se obstina en silenciar y desconsiderar. Se trata de una propuesta para reflexionar sobre cómo es posible sobrellevar la decadencia y la incapacidad física en este mundo moderno, desacralizado y secularizado, donde los grandes mitos religiosos sobre la naturaleza humana, el pecado, la culpa y la aceptación del sufrimiento han perdido legitimidad. Un mundo que parece negarse a prestarle la debida atención a un problema social creciente, el de la soledad de los moribundos (3, p. 11). En el momento de recibir la Palma de oro en Cannes, Haneke afirma que esta película responde a una inquietud personal, a la pretensión de buscar una respuesta para la siguiente cuestión: "Cómo administrar el sufrimiento de las personas que amamos".

Amour es un registro obsesivo, que en ciertos momentos parece adquirir el carác- ter de cine documental, del modo como se desarrolla el proceso de degradación física de Anne, una profesora de música octogenaria y ya retirada, después de haber sufrido un ataque que ha dejado como consecuencia una parálisis cerebral irreversible y progresiva. Anne convive con su marido Georges, también octogenario y profesor de música retirado. Es entorno a ese matrimonio que se desarrolla el drama. Siempre dentro de un mismo espacio cerrado, el interior de un confortable departamento de clase media de Paris, que poco a poco irá mostrando pequeños signos de decadencia y abandono. Es allí donde transcurre la vida de este matrimonio, impecablemente interpretado por Jean-Louis Trintignant y Emmanuelle Riva.

El trabajo de estos excelentes actores es lo que transforma a la película de Haneke en una verdadera obra de arte. Se trata de un trabajo actoral magistral que nos lleva a descubrir inmediatamente la complicidad y el amor de esa pareja que, como afirma Trintignant en una parte del filme, "han vivido muchos desafíos juntos, y ahora deben ver el mejor modo de vivir este nuevo momento de la vida" (1). Lo impecable del relato es que no se trata aquí de octogenarios aislados del mundo, sin amigos o próximos. Nada tiene que ver con esas historias trágicas que dejaron miles de ancianos muertos en París por una ola de calor en el año 2003. Allí se trataba de ancianos que vivían en situación de aislamiento por abandono de sus amigos, hijos o vecinos. Aunque el director parece jugar con esa ambigüedad en la primera escena del filme, la entrada abrupta de la policía en el departamento y la abertura inmediata de ventanas pueden llevarnos a imaginar que quieren evitar el olor a cadáveres en descomposición, aquí la narración es otra, y por ese motivo es tan importante el nombre elegido para este filme. 


\section{ENTRE LA VIDA Y LA MUERTE}

Haneke ha querido presentar una historia de amor, trágica, sin duda, pero que solo puede tener sentido dentro de una relación de afecto, respeto y dignidad. La segunda escena del filme nos muestra a Anne y Georges regresando del concierto de un ex alumno de Anne. Ya en esa escena se adivina una vida de complicidades y gustos compartidos, de buenos momentos que reaparecen una y otra vez. Por ejemplo, cuando Georges narra situaciones vividas en la infancia o juventud, ante la atenta e interesada escucha de Anne, o Eva recuerda cuando los escuchaba hacer el amor y entonces pensaba que siempre estarían los tres juntos, o cuando Anne le solicita a su marido su viejo álbum de fotografías. Allí vemos a Trintignant bello y vanidoso riendo en una mesa de amigos, a Emmanuelle Riva en el esplendor de su belleza y toda la dulzura de una Isabelle Huppert adolescente y de cabellos dorados. Cerrando el álbum de fotos, sin ningún dramatismo o sentimentalismo, Anne se limita a comentar: "tuvimos una vida larga y maravillosa". Y en esas palabras resuenan las palabras de Séneca cuando afirma: "Yo he vivido, querido Lucilio, tal como convenía: bien saciado de vivir, ahora aguardo la muerte" (2, p. 138).

Una de las escenas más logradas del filme es cuando Georges narra para Anne las situaciones vividas en el entierro de uno de sus amigos. Ese relato trasluce una impecable lucidez, un sentido crítico agudo y una inmensa capacidad de percibir ese límite tenue que suele separar lo digno de lo indigno, el decoro de lo vergonzoso. En ese relato Georges expone claramente su rechazo a repetir tradiciones por el simple hecho de respetarlas. Eso puede llevar a situaciones absurdas como cuando un cura habla en el entierro de su amigo como si lo conociera, aunque no lo conocía, o ese otro amigo invitado a dar un discurso que cae en el ridículo, o la ex secretaria que pone en un grabador la canción Yesterday, dejando atónitos a los presentes y provocando la risa de los nietos del difunto. Georges manifiesta su pena por la viuda, amiga de ambos, y define claramente su posición delante de las tradiciones que se mantienen por simple hábito.
Un párrafo aparte merece la figura de la hija de este matrimonio, Eva. Ella también es música y se encuentra en un momento muy vital y feliz de su carrera. Parece estar en plena actividad, vive en Londres con su marido y sus hijos, ya independientes. Narra sus compromisos en Londres, París y Holanda. Está impecablemente interpretada por Isabelle Huppert. Eva aparece y desaparece de la escena dejándonos un gusto extraño. Es una figura ambigua, preocupada por el estado de salud de su madre, quiere implicarse más en el proceso de cuidado, pero se encuentra con las barreras que le impone su padre. Georges y Anne no parecen ser de esos matrimonios que opinan que la obligación de los padres es cuidar a sus hijos, y que en la vejez, será a los hijos el turno del cuidado de los padres. Aquí no existe esa exigencia.

A Eva aún le queda mucho por vivir, planes por realizar, metas a conquistar. A ellos les toca saber lidiar con el fin de la vida, con la muerte que se aproxima, intentando preservarcierta autonomía para decidir hasta donde, y en qué momento, será preciso y necesario parar de aceptar el sufrimiento físico como si fuera una condena ineludible. Nada se le puede pedir a Eva, aunque ella no pretenda abandonarlos; al contrario, son ellos los que están deseosos de dar. Aún sin palabras Anne le dice a Eva que no se preocupe por una inversión en inmuebles, porque ese departamento en el que ahora viven, pronto será suyo. Y esa será justamente la escena final del filme: Isabelle Huppert sentada en la sala de su casa, donde antes conversara con su padre, después de la muerte de ambos. Una tradición más echada por tierra. Los hijos no vinieron al mundo para cuidar a sus padres en la vejez, sino para hacer sus propias vidas.

Dos mundos que se enfrentan, el de una vida que mira al futuro, simbolizada por una Eva implicada pero prepotente y soberbia, y el de una vida que ha llegado a su ocaso, y que mira hacia el pasado. En ese enfrentamiento resuenan muchas otras historias de hijos, generalmente de hijas mujeres, que renunciaron a sus vidas para, siempre al lado del lecho del enfermo, dedicarse durante largos años a esperar la llegada de la muerte de sus padres 
aquejados de enfermedades terminales. La literatura ha explorado esas vidas donadas a la muerte de manera enternecedora en la novela policial de Claudia Piñero (5), Elena sabe.

Allí, Piñero narra la historia de Rita, una hija ejemplar que cumple con el mandato de cuidar por largos años a su madre enferma de Parkinson. Más precisamente, narra la historia de su muerte y del penoso viaje que Elena emprende para descubrir al asesino de su hija. Esa búsqueda la llevará a descubrir una verdad dolorosa, que no existe asesinato, que Rita simplemente se ha suicidado porque ya no soportaba continuar siendo la madre de su madre. Si Elena sabe es un retrato de las consecuencias a las que conduce la aceptación de los mandatos sociales, Amour es, por el contrario, un relato angustiante del encierro en que se encuentran dos individuos que aún se aman en un mundo secularizado. Es que en nuestro mundo moderno libre de los lazos de las tradiciones, todavía no hemos sabido aceptar que es necesario pensar estrategias para administrar el peso aplastador del sufrimiento que antecede a la muerte, ni superar, como afirma Elias, la antipatía que los muertos y todo lo que a ellos se vincula, les produce a los vivos (3, p. 108).

La vida y la muerte de Rita (o de las tantas Rita que han poblado el mundo) no era el destino que Anne e Georges deseaban para Eva. Como afirma Georges en un momento del filme, ¿qué era lo que Eva podría hacer?: ¿Llevarse a su madre a su casa de Londres y ponerle una empleada? Eso él podía hacerlo, y todo estaba muy bien organizado. ¿Internarla en una institución para ancianos? Eso nadie podía hacerlo.Anne y Georges parecían tener muy claro que tanto el hospital como los asilos de ancianos pueden resumirse como “verdaderos desiertos de soledad" (3, p. 93).

\section{CUMPLIR CON LA PALABRA}

Es justamente ese drama el que articula la trama, y es entonces cuando ese maravilloso filme adquiere pertinencia para una reflexión filosófica sobre la polaridad entre la vida y la muerte propia de la condición humana. Es que, en el momento en que Georges discute con Eva, el pacto con Anne ya se ha sellado. Ella ya le había hecho prometer que nunca, pero nunca, la internarían en una institución de ancianos. A ese pedido Georges había respondido con una sola palabra "oui” (1). Desde entonces se aferrará a esa promesa por compañerismo, por amor, o simplemente por complicidad. Allí están en el fin de la vida dos personas que se han amado, que han amado a su hija, que han ganado el respeto y el cariño de los otros -vemos el claro aprecio que manifiestan el portero y su mujer y la admiración del ex alumno-, frente a frente con una corporeidad degradada que poco a poco lo irá tomando todo. Hasta que, finalmente, cada instante se transforme en un hecho difícil de sobrellevar. Hasta que cada momento y cada acto biológico como respirar, comer, caminar, hablar o defecar, se transforme en un verdadero tormento para ambos.

Aquí no hay castigo, ni culpa, ni pecado. Se trata de la naturaleza humana, de la finitud y la degradación a la que estamos sujetos todos, en la medida en que nuestra corporeidad nos impone esos procesos biológicos que son la vejez, la decadencia yla muerte.

Sabemos, sin embargo, que aunque no sea posible decidir o controlar lo que ocurrirá con nuestras venas, nuestros circuitos neuronales o nuestras células, aunque los sistemas médicos se obstinen en hacernos creer lo contrario, tenemos en nuestras manos la posibilidad de dar diferentes respuestas a eso que nos ocurre. Podemos aceptar la degradación física con resignación cristiana. Imaginar que se nos impone el deber sagrado de respetar la vida por sobre todas las cosas, independientemente de sus condiciones de existencia y dignidad. Podemos también desconocer los mandatos y tradiciones y decidir por nosotros mismos cuál es el mejor momento para detener un sufrimiento inevitable. Ejercer, en fin, ese último acto de libertad que Séneca considera inherente a la condición humana.

La degradación física de Anne encuentra su contrapartida en el afecto inmenso de Georges, que no quiere y no puede verla más sufrir y que ya no encuentra las fuerzas suficientes 
para sostener un proceso de degradación biológica que solo tiende a agravarse. De modo que podríamos repetir aquí la máxima de Séneca: "Antes de llegar a viejo procuraba vivir bien; en la vejez procuro morir bien, de buen grado" (2, p. 137). Si todo parece indicar que Anne y Georges han podido vivir bien, que han sabido llevar una buena vida, dedicados a la música, cultivando el afecto mutuo, el cariño de su hija y el respeto de los otros, es en ese momento que ha llegado la hora de procurar, o de intentar encontrar el modo de poder morir bien. Como afirma Séneca: "Morir más pronto o más tarde no tiene importancia, lo que sí la tiene es morir bien. No vale conservar la vida a cualquier precio" (2, p. 167).

\section{LA INEVITABILIDAD DE LA MUERTE.}

Haneke nos enfrenta al problema de la inevitabilidad de la muerte. Una ingenuidad generalizada parece haberse apropiado de esta temática, creyendo o fingiendo creer en mágicos poderes del saber médico para eternizarnos. En Amour, será Eva la encargada de personificar esta confianza ilimitada en los poderes de la ciencia. En ese contexto, la muerte huele a un fracaso colectivo o individual que debe ser ocultado, y por ello es que se condena a la intimidad, al silencio y al secreto todo el sufrimiento físico que la antecede. Haneke ha sabido hablar de aquello que nuestra sociedad se obstina en callar.

La decadencia, el sufrimiento físico y aun la muerte han dejado de ser pensados como hechos inherentes a la condición humana, para pasar a ser vistos en términos de ineficacia del sistema médico, o con mayor frecuencia aún, de alguna falta o descuido cometido por el propio enfermo o por sus cuidadores. En ese contexto debemos situar la exigencia de Eva a Georges, el reproche, completamente fuera de lugar, de no estar haciendo lo suficiente. De acuerdo a esa lógica, siempre se muere a destiempo, por no haber querido o sabido hacer lo suficiente. Haneke ha puesto en evidencia la necesidad de reflexionar sobre el derecho que nos asiste a todos los seres humanos a poder optar por una buena muerte, por una muerte digna. Una deuda aún pendiente, si recordamos que hace ya treinta años, Elias (3) insistía en la necesidad de comenzar a hablar abierta y claramente sobre la muerte y la soledad de los moribundos.

Amour se mete en ese tema silenciado y lo hace con maestría y valor. De lo que este filme nos habla no es de otra cosa que de la eutanasia, esto es, del derecho a una buena muerte, a morir conservando un resto de dignidad. Es verdad que otras películas retrataron el tema de la eutanasia, entre ellas Mar Adentro (6), interpretada por el versátil actor Javier Bardem. Pero allí, como en los muchos casos tematizados por la prensa y discutidos en foros de bioética, como el famoso caso de Karen Anne Quinlan, aunque se habla de situaciones tan reales como la retratada por Haneke, ellas están situadas en un espacio de reflexión absolutamente diferente.

Generalmente, los debates de la bioética actual giran en torno a la muerte digna en situaciones de encarnizamiento o ensañamiento terapéutico, donde el uso de aparatos de alta tecnología tienden a prolongar la vida más allá de cualquier posibilidad terapéutica, lo que se conoce con el nombre de Distanasia. En casos como estos, resulta necesario encontrar las medidas y los procedimientos legales para que sean desligados los aparatos que están llevando a una situación de sobrevida o de vida artificialmente sostenida, lo que en muchos casos constituye una verdadera batalla jurídica, muy bien retratada en Mar adentro (6).

Si aceptamos la distinción realizada por Giovani Berlinguer (7) entre, por un lado, una bioética de situaciones límites, preocupada por tematizar los problemas que surgen en el inicio y fin de la vida vinculados a la tecnología biomédica de punta, como el caso del clonaje, la selección de embriones para fecundación, la distanasia o encarnizamiento terapéutico, y, por otro, una bioética cotidiana que se preocupa por esas pequeñas muertes diarias que ocurren, ya no por exceso sino por falta de tecnología, de soporte terapéutico y de cuidado, que Berlinguer (7) llamó cacotanasia o mala muerte, el filme 
Amour se sitúa enteramente en este segundo registro. Aunque el tema es el fin de la vida, aunque la trama gire en torno a la eutanasia, no se trata aquí de confrontación con tecnologías duras de prolongamiento de la vida, se trata de parar para pensar en el más universal y cotidiano de los conflictos humanos: cómo morir con dignidad, o cómo hacer para poder "procurar en la vejez un morir bien". No es por acaso que Haneke, al recibir la Palma de oro en Cannes dedica este premio a su mujer, con quien convive hace 30 años y con quien realizó el mismo pacto que Anne y Georges, un pacto que, podemos imaginar, envuelve tanto el amor que da nombre a la película, como la muerte o el buen morir al que se refiere Séneca en las cartas a Lucilio.

Es por esa razón que Laura Lezcano puede afirmar: "En Amour, una historia de la infancia sirve de preludio para un clímax tan inesperado como triste. Haneke construye un retrato intenso y duro sobre la vejez, posicionándose sin miedo en el debate de la eutanasia. Y se merece una ovación: por atreverse con una historia de ancianos. Por filmar la muerte sin recurrir a efectismos. Por no manipular emocionalmente al espectador ni caer en sentimentalismos más falsos que un duro de chocolate. Por rodar una obra maestra".(8).

Se ha dicho diversas veces (8) que Haneke está obsesionado por el tema de la violencia. Aquí nos invita a interrogarnos si, frente a la imperiosa necesidad de detener el sufrimiento de alguien a quien se ama, era preciso recurrir a ese gesto final, cargado de una violencia que contrasta radicalmente con la mirada apacible de Georges, que tan magistralmente interpreta Trintignant en esa dolorosa escena. Entonces, podríamos repetir aquí la pregunta que Séneca formula en su elogio al suicidio de un gladiador: “¿Ello fue una injuria a la muerte? Sin duda fue poco delicada y poco decente la manera escogida, pero, ¿qué puede existir más necio que mostrarse delicado en la manera de matarse?” (2, p. 168). Para Séneca, la naturaleza nos ha puesto en una prisión abierta, no hay obstáculos para quien quiera escapar y cada uno deberá utilizar los medios que estén a su alcance: encontrará una salida suave aquel que tenga a mano recursos para hacerlo, a los otros les cabe "agarrarse con lo primero que encuentren, aunque pueda parecer insólito y sin precedentes” (2, p. 169). Recordemos que el propio Séneca se encontró frente a ese dilema cuando debió escoger su modo de morir, entonces escogerá el suicidio, negándose a aceptar una pena injusta impuesta por Nerón.

Frente al obstinado silencio y oscuridad a los que nuestra modernidad ha relegado esa realidad tangible y cotidiana que es el sufrimiento físico de muchos ancianos, solo parece haber restado un gesto privado, una decisión secreta que ocurre entre cuatro paredes. Un gesto de violencia, digámoslo para despejar dudas, que nada tiene que ver con aquella que por un supuesto amor, plagado de rencor, venganza y celos, miles de hombres dirigen, en el mundo entero, a las mujeres víctimas de su odio.

\section{UNA HISTORIA DE AMOR}

Resulta difícil pensar en el filme Amour sin recordar la historia de amor de André Gorz (4), relatada en su libro Carta a D. y en los sucesos que ocurrieron un año más tarde, cuando el 24 de septiembre de 2007 él y su mujer se quitaron la vida con una inyección letal. Entonces André Gorz, uno de los intelectuales más importantes del siglo XX, amigo personal de Sartre e Ivan Illich, cofundador del Nouvel Observateur, tenía 83 años y Dorine, de origen inglés, su interlocutora privilegiada y la primera lectora de cada uno de sus libros, 82.

Ella sufría una dolorosa enfermedad que la aquejaba desde hacía ya muchos años.Llevaban 58 años juntos, y ese día en la puerta de su casa solo había un papel que decía "Avisen a la policía”. Una amiga los encontró, lado a lado en el mismo lecho. Los motivos de este suicidio resultan evidentes cuando leemos el último libro publicado por Gorz (4), Carta a D.: Historia de un amor. El libro se inicia con las siguientes palabras: "Pronto tendrás 82 años. Has encogido seis centímetros, no pesas más que 45 kilos y continuas bella, graciosa y deseable. Ya hace 58 años que vivimos 
juntos, y yo te amo más que nunca. Otra vez cargo en mi pecho un vacío devorador que solamente el calor de tu cuerpo contra el mío es capaz de llenar" (4, p. 5).

Ese libro de inusual belleza, es un relato retrospectivo de los 58 años de vida en común de este matrimonio de intelectuales que compartía una visión del mundo y de la vida basados en la libertad de pensamiento, la defensa de la autonomía y las luchas contra las más variadas formas de sometimiento, incluyéndose allí una profunda critica a los abusos de la tecnomedicina. Uno de los textos publicados por Gorz en 1973, en ocasión del lanzamiento del libro de Ivan Illich Némesis de la medicina, llevaba el sugestivo título: "Cuando la medicina enferma". Poco más tarde descubrirá el alcance de esas palabras cuando se diagnostica a Dorine una enfermedad contraída como consecuencia de un tratamiento de hernia realizado años antes con lipiodol, una sustancia tóxica que se instaló en su médula raquídea.

Gorz relata los esfuerzos de Dorine por encontrar un soporte inicialmente en la medicina y luego en grupos de apoyo de portadores de la misma enfermedad. Más tarde Dorine será diagnosticada de cáncer de endometrio. Entonces, con 60 años, Gorz decide retirarse anticipadamente de su trabajo para dedicarse enteramente a acompañar a Dorine. Una larga peregrinación por médicos y por los últimos desarrollos tecnológicos, llevará a ambos a dedicarse al campo de la ecología, de la tecno crítica y al estudio de las medicinas alternativas. "La tecnomedicina -afirma Gorz- me parecía una forma particularmente agresiva de aquello que Foucault, más tarde, llamaría biopoder, ese poder que los dispositivos técnicos asumen hasta sobre la relación íntima de cada uno consigo mismo" $(4$, p. 64$)$.

Esa preocupación por los límites y posibilidades del conocimiento científico recorre sutilmente la narración de Amour. Es que Eva no se resigna a que nada pueda hacerse; ella quiere buscar nuevas técnicas, nuevas estrategias terapéuticas, insiste de un modo fatigante y soberbio en que se está haciendo poco, que no hay suficiente saber médico en juego. Georges, por el contrario entiende, como André Gorz, que se trata de estar allí, de acompañar el día a día de ese sufrimiento como se pueda, en este caso con una enfermera que irá tres veces por semana, con una visita quincenal del médico y otra de la peluquera. En el caso de Gorz, cultivando el placer de cocinar, de buscar productos orgánicos y de cuidar la preparación de las fórmulas homeopáticas magistrales que le habían recetado a Dorine.

Lo cierto es que, según leemos en Carta a D., del mismo modo que Anne y Georges, André y Dorine también habían sellado entre ellos un pacto, que Gorz describe de este modo: "Éramos, vos y yo, hijos de la precariedad y el conflicto. Fuimos hechos para protegernos mutuamente y precisábamos crear juntos, uno para el otro, el lugar en el mundo que nos había sido negado. Para eso sería necesario que nuestro amor fuera también un pacto para la vida”. (4, p. 15).

No conocemos la historia de Anne y Georges con la misma precisión, no sabemos si ellos son o no hijos de la precariedad y el conflicto. Sabemos sí lo que Haneke quiso mostrar, una relación intima tan profun$\mathrm{da}$, solidaria y respetuosa como la que Gorz narra conmovedoramente y en detalle en su libro. Sabemos también que se trata de vínculos donde resulta casi imposible pensar la existencia de uno sin el otro. Quizás sea por eso que Georges no duda en aceptar el pacto propuesto por Anne. Internarla significaría continuar su camino sin ella, y eso parecía estar fuera de cuestión. Continuar juntos hasta el fin fue el modo que ellos encontraron para huir de la soledad.

Dos pesadillas son narradas en estas historias, dos pesadillas que indican un mismo terror, el terror a la soledad o al abandono. En una escena del filme, Georges despierta angustiado después de haber soñado que se ausentaba del departamento por algunos instantes y no podía regresar, una mano en su boca le impedía respirar, el agua le llegaba a los tobillos en un corredor inundado de un edificio abandonado donde solo se escuchaba la voz de Anne llamándolo y sin que él pudiera responder. El terror de una separación 
inútil e innecesaria también adopta en Gorz la forma de una pesadilla. "A la noche yo veo a veces la silueta de un hombre en una calle vacía y en un paisaje desierto, él anda atrás de un coche fúnebre. Yo soy ese hombre. Y ese carro te lleva a vos" (4, p. 71).

De lo que se trata en ambos casos, visto desde una perspectiva jurídico- médica, o aun desde la perspectiva de la bioética, es de dos casos de eutanasia o suicidio asistido. Sin embargo hay algo más que está en juego, algo muy íntimo que se enuncia en ambos casos y que se refiere al deseo explícito de no querer sobrevivir uno a la muerte del otro. Se trata de un tipo de amor romántico que no puede dejar de conmovernos en tiempos de “amor líquido”. Un tipo de amor romántico que nada tiene que ver con aquel retratado por Giddens (9) en La Transformación de la intimidad. No está basado en celos, en mitos de una totalidad perdida, ni en tradiciones sociales o religiosas; es la persistencia del amor romántico en lo que Giddens llamaría formas de relacionamiento puro, ambos sostenidos por vínculos de respeto, autonomía y libertad.Ese es el modo que estos dos matrimonios han encontrado para escapar de la creciente soledad a la que el mundo contemporáneo ha condenado a los moribundos. Ellos parecen saber muy bien que "jamás anteriormente ha muerto la gente de una manera tan higiénica como hoy en día, y jamás lo ha hecho en unas condiciones que hayan fomentado tanto la soledad"(3, p. 105).

\section{PARA CONCLUIR}

Digamos por fin, que en ambos casos se hace uso de un mismo recurso narrativo, existe un juego de recurrencia y circularidad entre el inicio y el fin de las obras que está presente tanto en Amour como en Carta a D. Ese recurso narrativo aparece, sin embargo de manera diferente en ambos casos. En Gorz adopta la forma de una declaración de amor: "Acabaste de cumplir ochenta y dos años y continúas bella, graciosa y deseable” (4), con esta frase se inicia y concluye el texto. En Amour lo que se repite es una escena de violencia, la policía derribando la puerta del departamento e ingresando con impaciencia, abriendo las ventanas para dejar entrar el aire en ese departamento donde transcurrió la historia y la muerte de ambos. Entonces la policía encontrará el cadáver de Anne cuidadosamente dispuesto en su lecho y rodeado de flores y, lo adivinamos, a Georges sin vida. Del mismo modo que, el 24 de septiembre de 2006 la policía encontrará el cuerpo de André y Dorine. Es que "el hecho de morir, se mire como se mire, es siempre un acto de violencia” (3, p. 108).

Entre el inicio y el fin de los relatos, un mismo pacto de solidaridad, de amor y de compañerismo. Un pacto que la narrativa de Gorz describe con precisión: "No quiero asistir a tu cremación. No quiero recibir una urna con tus cenizas. Escucho la voz de Ferrier cantando: 'El mundo está vacío, no quiero más vivir' y desespero. Nosotros no desearíamos tener que sobrevivir uno a la muerte del otro" (4, p. 71).

De lo que se trata en ambos casos, es de poner en evidencia que en nuestras sociedades desarrolladas no hemos podido aún resolver los problemas que plantea el hecho de morir, la soledad, el sufrimiento físico, o el abandono de quien permanece. Como afirma Elias: "Puede decirse que todavía no acabamos de darnos cuenta de que el morir trae consigo, en las sociedades desarrolladas, una serie de problemas específicos que todavía no afrontamos como tales" (3, p. 109). Con simplicidad, elegancia y dureza Amour es una invitación para pensar esos problemas y los posibles modos de resolverlos.

La pregunta que ha llevado a Haneke a realizar este maravilloso filme podría entonces transformarse. En estos casos no se trata solo de intentar comprender cuál es el mejor modo de administrar el sufrimiento de las personas que amamos, cuando nos encontremos frente a ese sufrimiento, sino de intentar entender cómo, al final de una bella y larga vida, estas personas han podido administrar el sufrimiento del otro y su propio sufrimiento de modo tal de poder, como lo hubiera deseado Séneca, "encontrar en la vejez una buena muerte”. 


\section{REFERENCIAS}

1. Haneke, M. (Director) Amour. Paris, Viena: Imovision, Estúdio: Les Films du Losange / X-Filme Creative Pool / Wega Film. 2012; http://www.golem.es/distribucion/pelicula. php?id=277

2. Séneca, L. Cartas Morales a Lucilio. Buenos Aires: Hispamérica. 1984.

3. Elias, N. La soledad de los moribundos. México: FCE. 1989.

4. Gorz, A. Carta a D: uma historia de amor. São Paulo: Ed. Cosac Naify-Annablume. 2008.
5. Piñero, C. Elena Sabe. Buenos Aires: Alfaguara. 2007.

6. Amenábar, A. Mar adentro. Madrid. París: Union Générale Cinématographique (UGC) / Televisión Española (TVE) / Canal+. País: Espanha/ França/ Itália. 2004.

7. Berlinguer, G. Bioética cotidiana. México: Siglo XXI. 2002.

8. Lezcano, L. Crítica de cine: Amour [consultado 11.02.2013]. http://www.lapalomitamecanica.com/2013/01/critica-de-cine-amour.html

9. Giddens, A. A transformação da Intimidade: Sexualidade, Amor e erotismo nas sociedades modernas. São Paulo: Ed. Unesp. 1993. 